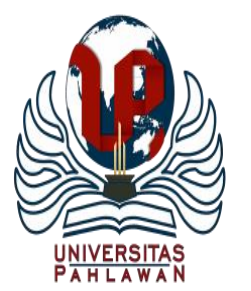

Jurnal Abdidas Volume 1 Nomor 5 Tahun 2020 Halaman 424 - 429

JURNAL ABDIDAS

Community Development Service on Educational and Health Sciences http://abdidas.org/index.php/abdidas

\title{
Optimalisasi Pengembangan Kelompok Usaha Sagu Jai di Kelurahan Jaya Kota Tidore Kepulauan
}

\author{
Muhlis Hafel ${ }^{1}$, Mohbir Umasugi ${ }^{2}$, Rheza Pratama ${ }^{3}$, Suhardi $^{4}$ \\ Universitas Terbuka, Indonesia ${ }^{1,2}$ \\ Universitas Khairun, Maluku Utara, Indonesia ${ }^{3,4}$ \\ E-mail : muhlis@ecampus.u.ac.id ${ }^{1} \underline{\text { mohbir@ecampus.ut.ac.id }} \underline{\text { rhezapratama@unkhair.ac.id }}$ \\ suhardiuim@gmail.com ${ }^{4}$
}

\begin{abstract}
Abstrak
Kelurahan Jaya terdapat 5 (lima) kelompok tani yang aktif menjalankan usaha pembuatan sagu jai. Peluang usaha produksi sagu jai memiliki prospek pasar yang menjanjikan, namun dalam pengembangannya kelompok usaha sagu jai terkendala masalah manajemen, produksi dan strategi promosi dari kelompok tersebut. Dalam menyelesaikan permasalahan mitra diatas diperlukan sebuah metode pelaksanaan yang efektif, yaitu pendekatan partisipatif. Metode partisipatif yang dipakai berupa pendampingan dari sisi manajemen, produksi dan promosi/pemasaran. Pelatihan PKM ini memberikan solusi terkait aspek pemasaran dan penjualan melalui pemasaran digital dengan memanfaatkan media sosial yang ada untuk meningkatkan omzet penjualan sagu jai. Hasil dari program PKM yang dilaksanakan ini adalah meningkatnya usaha serta kapasitas produksi dalam memenuhi kebutuhan pasar untuk produk sagu jai. Selain itu, Pelatihan PKM ini memberikan solusi terkait aspek pemasaran dan penjualan melalui pemasaran digital dengan memanfaatkan media sosial yang ada untuk meningkatkan omzet penjualan sagu jai di kota Tidore Kepulauan.
\end{abstract}

Kata kunci: optimalisasi produksi, manajemen, pemasaran

\section{Abstract}

Jaya Village has 5 (five) farmer groups that are active in making sago jai. The sago jai production business opportunity has promising market prospects, but in its development the sago jai business group is constrained by management, production and promotion strategy problems from the group. In solving the above partner problems, an effective implementation method is needed, namely a participatory approach. The participatory method used is in the form of assistance in terms of management, production and promotion / marketing. This PKM training provides solutions related to marketing and sales aspects through digital marketing by utilizing existing social media to increase the sales turnover of sago jai. The result of this PKM program being implemented is an increase in business and production capacity to meet market demand for sago jai products. In addition, this PKM Training provides solutions related to marketing and sales aspects through digital marketing by utilizing existing social media to increase the sales turnover of sago jai in the city of Tidore Islands.

Keywords: production optimization, management, marketing

Copyright (c) 2020 Muhlis Hafel, Mohbir Umasugi, Rheza Pratama, Suhardi

$\triangle$ Corresponding author :

Address : Kota Ternate

Email: : muhlis@ecampus.u.ac.id

ISSN 2721-9224 (Media Cetak)

Phone : 081282974368

ISSN 2721-9216 (Media Online)

DOI : https://doi.org/10.31004/abdidas.v1i5.96 


\section{PENDAHULUAN}

Kelurahan Jaya Kecamatan Tidore Utara Kota Tidore Kepulauan merupakan salah satu kelurahan yang sebagian besar masyarakatnya berprofesi sebagai petani. Kelurahan Jaya terdapat 5 (lima) kelompok tani yang aktif menjalankan usaha pembuatan sagu jai. Setiap kelompok tidak sekedar mengolah kasbi menjadi produk olahan sagu, namun melakukan proses budidaya Ubi Kayu (Kasbi) untuk dijadikan bahan baku pembuatan sagu. Proses produksi sagu jai dilakukan secar kontinue dan dibuktikan pada Gambar 1.

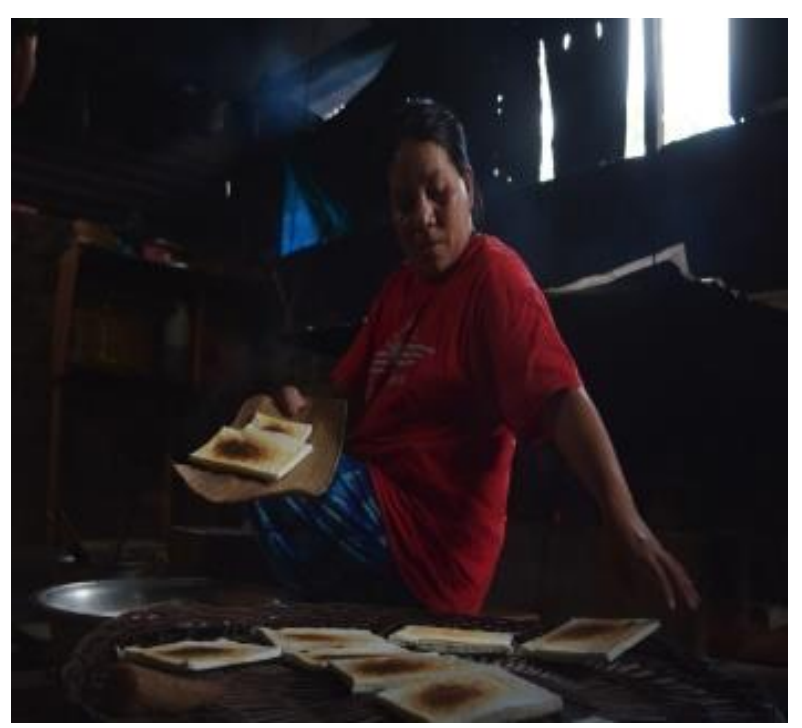

Gambar 1. Proses Pembuatan Sagu Jai

Kelompok Usaha Wanita Tani yang berdiri sejak tahun 2010 memiliki visi dan misi untuk meningkatkan tingkat kesejahteraan kelompoknya yang memanfaatkan komoditi kearifan lokal sebagai bahan dasar produknya (sagu). Selain itu, kelompok usaha ini didirikan untuk memanfaatkan potensi sumber daya pangan yang banyak dibudidayakan di Kelurahan Jaya (Kaddas, 2013).
Usaha sagu kasbi didirikan untuk memenuhi permintaan pasar lokal di Provinsi Maluku Utara khususnya di Kota Tidore Kepuluan. Kebutuhan sagu lempeng yang diproduksi oleh Kelompok Usaha Sagu Jai sangat diminati karena memiliki cita rasa dan karakterisitik yang berbeda dari produk yang sejenisnya, oleh sebab itu peluang usaha produksi sagu jai memiliki prospek pasar yang menjanjikan, namun dalam pengembangannya kelompok usaha sagu jai terkendala masalah manajemen, produksi dan strategi promosi dari kelompok tersebut.

Berdasarkan permasalahan diatas maka kami Tim Pengabdian kepada Masyarakat dosen Universitas Terbuka melihat hal ini sebagai potensi yang perlu dioptimalisasikan dan dikembangkan agar meningkatkan taraf kesejahteraan masyarakat melalui Kelompok Usaha Sagu Jai dan masyarakat sekitarnya.

Mengaju pada butir analisis situasi, yaitu berdasar pada hasil identifikasi masalah ditemukan dua masalah utama yang dihadapi Kelompok Usaha Sagu Jai (Mitra), yaitu: (1) belum optimalnya manajemen dan sektor produksi yang dilakukan, (2) kelompok juga belum mengenal strategi promosi yang efektif untuk mengenalkan produknya (sagu) pada pasar. Dengan mempertimbangkan hal di atas, maka disepakati bahwa akan diatasi pada program pengabdian adalah masalah manajemen usaha, optimalisasi produksi dan strategi promosi yang efektif dalam melakukan pengembangan usaha. Sehingga mampu menjadi alternatif bagi masalah kosongnya produk sagu di Kecamatan Tidore Utara (Tidore dan sekitarnya). 


\section{METODE}

Dalam menyelesaikan permasalahan mitra diatas diperlukan sebuah metode pelaksanaan yang efektif. Metode yang dipakai berupa pendampingan dari sisi manajemen, produksi dan promosi/ pemasaran (Asnawia, 2017). Kesepakatan tersebut diwujudkan dalam bentuk strategi yang menggunakan tahapan metode sebagai berikut: (1) Bidang manajemen, yaitu dengan melalui pendampingan peningkatan kompetensi pengusaha agar mampu memasarkan produk secara lebih baik, pembuatan kemasan yang sudah divacum menjadi keunggulannya, (2) Bidang produksi, di bidang produksi dilakukan dengan meningkatkan kualitas produk melalui pemutakhiran fasilitas dan kompetensi dalam mengolah, dan (3) Bidang Promosi/Pemasaran, dilakukan dengan melalui pendampingan pembuatan media promosi, iklan di media lokal (MalutPost) dan menyuplai produk di berbagai tempat yang strategis.

Pemerintah Kelurahan Jaya Kota Tidore Kepulauan, serta komponen-kompenen masyarakat yang berada di lingkungan Jaya sebagai mitra akan berpartisipasi aktif dalam kegiatan Pengabdian Kepada Masyarakat (PkM) tentang Optimalisasi Pengembangan Kelompok Usaha Sagu Jai di kelurahan Jaya Kota Tidore Kepulauan.

Ketua Kelompok usaha Sagu Jai yakni Ibu Saefa Hasan mengatakan pihaknya siap berpatisipasi dan mensukseskan kegiatan PKM tentang Optimalisasi Pengembangan Kelompok Usaha Sagu Jai di kelurahan Jaya Kota Tidore Kepulauan. Bentuk partisipasinya adalah dengan melibatkan peserta dalam kegiatan PKM ini dari berbagai unsur diantaranya:

a. Kantor Keluruhan Jaya

b. Ketua RT/RW Lingkungan Jaya TugufaraJaimayou Keluarahan Jaya

c. Masyarakat Kelurahan Jaya

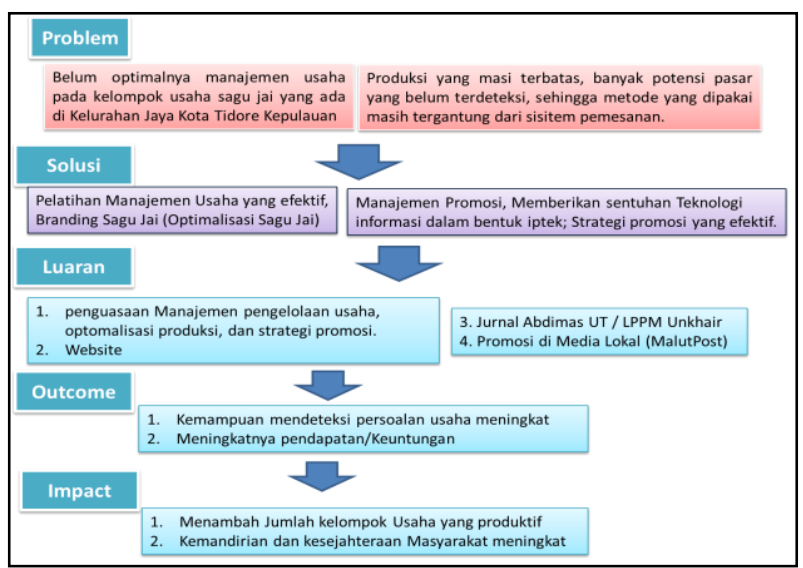

Gambar 2. Kerangka Pikir Metode Pelaksanaan PKM

\section{HASIL DAN PEMBAHASAN}

Dalam pelaksanaan survei pendahuluan ini dilakukan di Kelurahan Jaya, Kecamatan Tidore Selatan, Kota Tidore Kepulauan dengan mitra sasaran pelaksanaan program Pengabdian Kepada Masyarakat adalah Kelompok Wanita Tani Kelurahan Jaya. Adapun hasil dari pelaksanaan survei pendahuluan ini antara lain:

1. Kelurahan Jaya adalah salah satu kelurahan yang merupakan sentra produksi sagu jai.

2. Sebahagian besar masyarakat Jaya menggantungkan hidup di sektor pertanian perkebunan dengan komoditi utama ketela pohon atau dikenal dengan nama lokal (kasbi).

3. Rendahnya pengetahuan tentang manajemen pemasaran pengelolaan sagu jai. 
4. Keterbatasan alat dalam mengolah kasbi menjadi sagu jai.

5. Rendahnya pengetahuan dalam memanfaatkan media online dalam pemasaran produk.

Berdasarkan hasil survei yang dilakukan oleh tim pelaksana kegiatan PKM diatas maka adanya kesepahaman dan kesepakatan untuk dilaksanakan kegiatan pengabdian kepada masyarakat dengan lokasi kegiatan dilakukan di Kelurahan Jaya dengan mitra Kelompok Wanita Tani Kelurahan Jaya. Tema kegiatan yang dirumuskan pada kegiatan pengabdian ini adalah “Optimalisasi Pengembang-an Kelompok Usaha Sagu Jai di Kelurahan Jaya Kota Tidore Kepulauan.”

Pelaksanaan kegiatan Pengabdian Kepada Masyarakat dilakukan pada hari Sabtu, tanggal 15 Agustus 2020 di Kelurahan Jaya Kota Tidore Kepulauan dengan peserta kegiatan adalah Anggota Kelompok mitra yaitu Kelompok Usaha Wanita Tani Kelurahan Jaya. Pelaksanaan kegiatan Pengabdian Kepada Masyarakat dilakukan dengan didasarkan pada pelaksanaan survei pendahuluan yang telah dilakukan sebelumnya, dimana teridentifikasi permasalahan yang dihadapi oleh mitra sehingga pelaksanaan kegiatan dihadiri oleh Dr. Muhlis Hafel, M.Si sebagai Ketua Tim Pelaksana Kegiatan dan Rheza Pratama, SE.,M.Si serta Suhardi, S.P.,M.Si sebagai anggota Tim. Penyampaian materi pada pelaksanan kegiatan oleh narasumber dapat diuraikan dalam Tabel 1.

Ketercapaian tujuan pelatihan dengan metode pendampingan pengembangan media pelatihan secara umum sedah baik, namun keterbatasan waktu yang disediakan mengakibatkan tidak semua materi tentang optimalisasi produksi dan pemasaran digital dapat disampaikan secara detail. Namun dilihat dari hasil latihan para peserta yaitu kualitas media pelatihan yang telah dihasilkan, maka dapat disimpulkan bahwa tujuan kegiatan ini dapat tercapai.

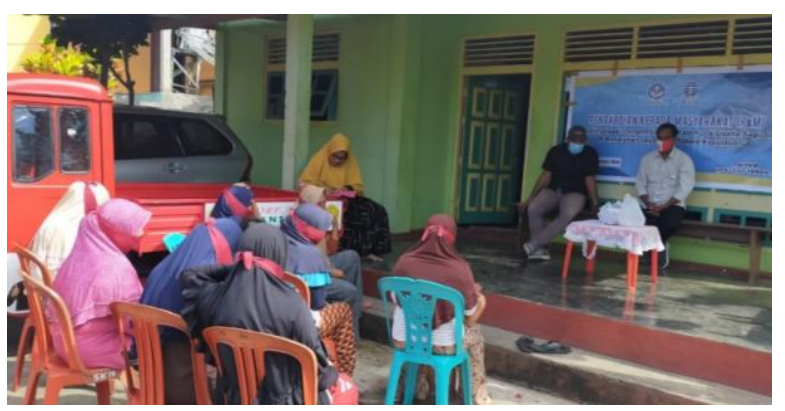

Gambar 3. Pelaksanaan Pelatihan

Tabel 1. Pokok Materi Kegiatan

\begin{tabular}{|l|l|l|l|}
\hline No & \multicolumn{1}{|c|}{ Nama Pemateri } & \multicolumn{1}{c|}{ Materi } & \multicolumn{1}{c|}{ Deskripsi Materi } \\
\hline 1 & Dr. Muhlis Hafel., M.Si & $\begin{array}{l}\text { - Manajemen Bisnis } \\
\text { - Kebijakan bisnis } \\
\text { Pemerintah }\end{array}$ & $\begin{array}{l}\text { - Merancang, mengelola dan } \\
\text { mengoperasikan sebuah usaha } \\
\text { atau bisnis. } \\
\text {-Kebijkan Pem erintah tentang } \\
\text { pengelolaan Bisnis }\end{array}$ \\
\hline 2 & Suhardi, SP., M.Si & $\begin{array}{l}\text { Optimalisasi } \\
\text { Produksi Usaha } \\
\text { Pertanian }\end{array}$ & $\begin{array}{l}\text { Mengoptimalkan Sum berdaya } \\
\text { yang digunakan agar suatu } \\
\text { produksi }\end{array}$ \\
\hline 3 & Rheza Pratama, SE., M.M & $\begin{array}{l}\text { Pemasaran Digital } \\
\text { Strategi m empromosikan } \\
\text { sebuah produk dengan } \\
\text { menggunakan media digital. }\end{array}$ \\
\hline
\end{tabular}


Ketercapaian target materi pada kegiatan PKM ini cukup baik, karena materi pelatihan telah dapat disampaikan secara keseluruhan. Materi pelatihan yang telah disampaikan adalah:

1. Manajemen Pengelolaan Usaha

2. Optimalisasi Produksi Usaha

3. Manajemen Pemasaran Digital

Kemampuan peserta PKM dilihat dari penguasaan materi lumayan mendapatkan antusias namun waktu yang singkat dalam penyampaian materi dan kemampuan para peserta yang berbedabeda ini yang menjadi catatan bagi Tim PKM untuk melakukan pendampingan pasca pelaksanaan kegiatan. Hal ini juga disebabkan jumlah materi yang lumayan banyak hanya disampaikan dalam waktu sehari sehingga tidak cukup waktu bagi para peserta untuk memahami dan mempraktekkan secara lengkap semua materi yang diberikan.

Solusi terhadap permasalahan untuk program PKM ini adalah mendorong partisipasi masyarakat dalam tahap implementasi. Implementasi yang dimaksud adalah keterlibatan di dalam optimalisasi pengelolaan usaha produksi sagu jai sehingga mampu berkembang dan menjadi salah satu produk unggulan yang berasal dari kota Tidore Kepulauan (Pratama, 2019).

Langkah strategis selanjutnya adalah mengadakan program pengabdian yang terprogram pada semua kelompok usaha sagu jai yang ada di kelurahan Jaya Kota Tidore Kepulauan, sehingga dampak dari program kegiatan PKM ini kedepan bisa lebih luas dalam meningkatan taraf kesejahteraan kelompok-kelompok usaha sagu jai secara menyeluruh yang ada di Kelurahan Jaya
(Timisela, 2016). Kemudian, dilakukan sebuah penelitian yang berdasar dari program PKM ini sehingga kedepan tim memperoleh data yang lebih akurat dalam pengambilan keputusan dan membuat rekomendasi yang tepat untuk optimalisasi pengelolaan sagu jai di Kota Tidore Kepulauan. Selanjutnya, demi terwujudnya tujuan bersama dalam optimalisasi usaha sagu jai, maka sinergi antara pemerintah dan pelaku usaha harus terprogram dan terukur demi hasil yang berkelanjutan dari tahun ke tahun.

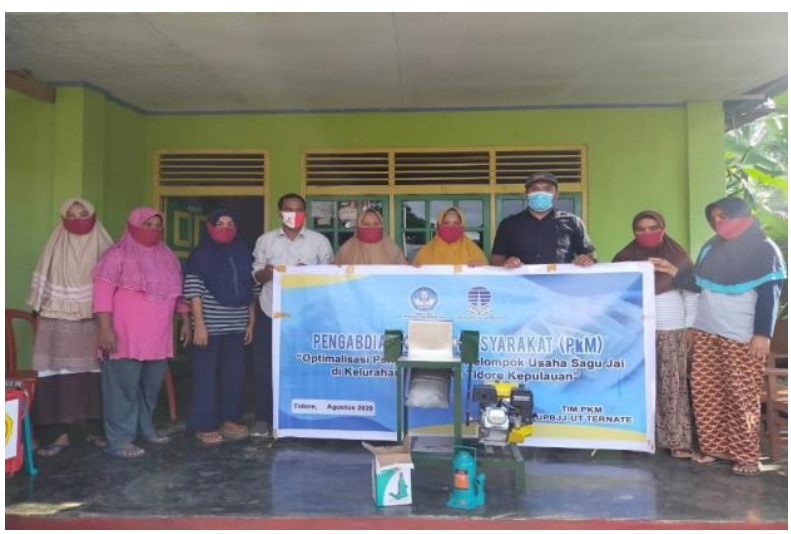

Gambar 4. Penyerahan Bantuan PKM

\section{SIMPULAN}

Berdasarkan hasil penelitian dan pengadian yang diadakan di Keluarahan Jaya, tempat ini memiliki banyak sekali potensi, terutama di bidang pertanian dan usaha sagu jai. Kedua potensi ini masih sangat mungkin untuk dikembangkan melalui program pelatihan dan pendampingan yang berkelanjutan. Melalui program PKM yang dilaksanakan ini meningkatan usaha serta kapasitas produksi dalam memenuhi kebutuhan pasar untuk produk sagu jai. Selain itu, pelatihan PKM ini memberikan solusi terkait aspek pemasaran dan penjualan melalui pemasaran digital dengan 
memanfaatkan media sosial yang ada untuk meningkatkan omzet penjualan sagu jai.

Dengan program PKM yang di danai Universitas Terbuka pengembang usaha sagu jai dapat dilakukan dengan model yang lebih partisipatif dan kolaboratif, yang mana dapat menjadi cara efektif dalam menyelesaikan persoalan kelompok usaha sagu jai yang terkendala masalah manajemen, produksi dan strategi promosi. Keterlibatan semua pihak juga menjadi syarat utama dalam mengoptomalisasikan usaha sagu jai agar menjadi produk unggulan dari Kota Tidore Kepulauan. Selanjutnya, demi terwujudnya tujuan bersama dalam optimalisasi usaha sagu jai, maka sinergi antara pemerintah dan pelaku usaha harus terprogram dan terukur demi hasil yang berkelanjutan dari tahun ke tahun.

\section{DAFTAR PUSTAKA}

Asnawia, Saud Ilham Maulana, W. (2017). Peningkatan Mutu Produk dan Pemasaran Olahan Ikan Bandeng. Berdikari, 1(Ekonomi dan Bisnis), 11-21.

Kaddas, F. (2013). Agribisnis Sagu Ubi Kayu Di Kelurahan Jaya, Kecamatan Tidore Utara, Tidore Kepulauan Disusun Oleh: Fatmawati Kaddas, SP. M.Si. Universitas Patimura, VI(Agribisnis), 31-37.

Lawalata, M., \& Luhukay, J. M. (2019). Pangan Lokal Berbasis Ubi Kayu Ditinjaudari Segi Produksi Dan Konsumsi (Studi Kasus Desa Waai Kecamatan Salahutu Kabupaten Maluku Tengah). Agrilan: Jurnal Agribisnis Kepulauan, 6(1), 92-111.

Pratama, R. (2020). Pengantar Manajemen. Deepublish.

Pratama, R. (2019). Pengaruh Modal, Lokasi dan Jenis Dagangan Terhadap Pendapatan Pedagang Pasar. Jurnal Mitra Manajemen, 2(4), 273-285. http://e- jurnalmitramanajemen.com/index.php/jmm/a rticle/view/125/69

Timisela, N. (2016). Analisis Usaha Sagu Rumahtangga dan Pemasarannya. Faperta Unpati, December 2006. https://www.researchgate.net/publication/298 698070 